\title{
Side Lobe Level Reduction of Phased Array Using Tchebyscheff Distribution and Particle Swarm Optimization
}

\author{
Pampa Nandi ${ }^{1}$, Jibendu Sekhar Roy ${ }^{2}$ \\ ${ }^{1,2}$ School of Electronics Engineering, KIIT University, Odisha, India \\ 1 pampanandi@yahoo.com \\ ${ }^{2}$ drjsroy@rediffmail.com
}

\begin{abstract}
Phased array antenna produces highly directive beam along with high side lobe level (SLL) which causes interference in other directions and level of side lobe changes with beam steering. To mitigate such constraint, in this paper, particle swarm optimization (PSO) is applied along with Tchebyscheff distribution (TD) to the linear phased array antenna. Simulating radiation patterns of linear phased array antenna at different scanning angles, using Tchebyscheff distribution, particle swarm optimization and combined Tchebyscheff distribution with particle swarm optimization (TD-PSO) are compared. Maximum side lobe level is reduced by $11 \mathrm{~dB}$ using TD-PSO method than Tchebyscheff distribution method. Better SLL suppression was obtained using TD-PSO but with slight increase of the main null to null beamwidth, compared to TD array. The research work presented here may be useful for radio navigation and satellite communication where phased array antennas are widely used.
\end{abstract}

Keyword - Tchebyscheff distribution, phased array, side lobe level, particle swarm optimization

\section{INTRODUCTION}

In phased array antenna resulting radiation pattern is steered at any particular direction by changing electronically the relative phase of feed current between the antenna elements in the array [1-3]. Phased array antenna is widely used for RADAR, satellite communication and other vehicular applications. The main drawback of phased array is higher side lobe level which changes with beam tilting and causes interference. Various methods of designing phased array with lower side lobe levels can be found in literature [4-9]. Statistically tapered amplitude arrays based on empirical or analytical formula found application in array synthesis methods to reduce side lobe level with maintaining the desired gain [4-7]. Tchebyscheff array is very well known optimal array pattern synthesizing method for the linear array where individual element fed with the current value equal to the Tchebyscheff coefficient and the resulting array pattern produces fixed lowest side lobe level for a particular beamwidth [7]. A method for finding optimum weights for minimizing side lobe level of arbitrary linear array is described in [6].

There are various proposed strategies and methods where by tapering the feeding current amplitude of elements, side lobe levels are reduced [4-6, 8, 9]. One of the methods for side lobe suppression and beam control is to use optimization techniques. For antenna array applications, popular optimization techniques are genetic algorithm, ant colony optimization, simulated annealing, particle swarm optimization [10-16]. Differential equation with back tracking search algorithm is applied to reduce side lobe level of concentric circular array [10]. Null placing and minimizing the side lobe level during scanning of a linear array antenna using Pareto optimal synthesis procedure is described in [11]. Thinning is another technique of side lobe level reduction of linear array [16]. The problem of phased array is with tilting of beam from broadside direction, the possibility of appearance of grating lobe increases.

In this paper linear phased array antenna is designed to tilt the main beam at different angles from the broadside direction and Tchebyscheff distribution is used to control the current fed in each antenna of the array, for a certain SLL. Afterwards PSO is applied to further reduction of side lobe level without much increase in main beamwidth. Theory of phased array and cost function, used for optimization, are described briefly in section 2, the simulated results for side lobe level reduction are presented in section 3, the performances of the PSO and TD-PSO optimized arrays with Tchbyscheff array are also compared and discussed in section 3. Computed results show that the proposed method of side lobe level reduction using Tchebyscheff distribution with PSO (TD-PSO) achieves about maximum $11 \mathrm{~dB}$ lower SLL than phased array designed using only Tchebyscheff distribution (TD). 


\section{PHASED ARRAY ANTENNA AND FORMULATION OF COST FUNCTION}

Consider a uniformly spaced linear array (Fig. 1) of $\mathrm{N}$ elements with a fixed distance between any two adjacent elements, $d$. The array is operated at wave length $\lambda$, wave number $\beta=2 \pi / \lambda$, fed with current excitation $\mathrm{I}_{\mathrm{n}}$ with progressive phase shift $\alpha$.

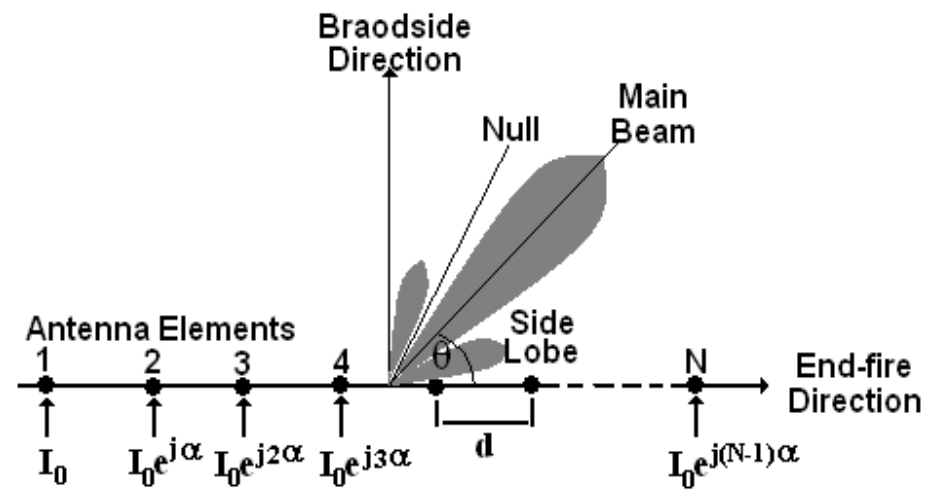

Fig. 1. Uniform linear antenna array

The array factor of the phased array at scanning angle $\theta_{0}$ is [1-3]

$$
A F_{L}=\sum_{n=1}^{N} I_{n} e^{j n \beta d\left(\cos \theta-\cos \theta_{0}\right)}
$$

When each element of phased array antenna fed by the current weight equivalent to Tchebyscheff coefficient then the resulting tapered antenna produces fixed equi ripple side lobe for a fixed beamwidth. For $\mathrm{m}^{\text {th }}$ order Tchebyscheff polynomial the coefficient $\mathrm{T}_{\mathrm{m}}$ can be calculated as [7]

$$
\begin{array}{cc}
T_{m}(x)=\cos \left(m \cos ^{-1} x\right) & -1<x<+1 \\
T_{m}(x)=\cosh \left(m \cos ^{-1} x\right) & |x|>+1
\end{array}
$$

When applying the Tchebyscheff distribution for array synthesis, it tapers current distribution in the array to design narrowest beamwidth for a certain side lobe level (SLL), conversely, synthesize array with lowest SLL for a certain beamwidth. If number of elements in the array is $\mathrm{N}$, then $\mathrm{m}=\mathrm{N}-1$ will be the number of nulls in the radiation pattern. The function $\mathrm{T}_{\mathrm{m}}(\mathrm{x})$ is shaping the radiation pattern consisting of one major lobe with several fixed SLL [7] with maintaining their amplitude ratio $1 / b$. The beamwidth is directly related to $b$ and the position of main beam, $\mathrm{x}_{0}$, which can be expressed as [7]

$$
\mathrm{T}_{\mathrm{m}}\left(\mathrm{x}_{0}\right)=\mathrm{b}, \quad b=\cos \rho, \quad \mathrm{x}_{0}=\cosh (\rho / \mathrm{m})
$$

The linear phased array is excited with the current value of Tchebyscheff coefficient. The resulting Tchebyscheff array produces array factor $\mathrm{AF}$, which is determined as

$$
A F=A F_{L} T_{m}(x)
$$

The maximum side lobe level of the observed pattern

$$
S L L R=\max \left|\frac{A F_{L}(\theta)}{\max \left(A F_{L}\right.}\right|_{\theta=\theta_{S L L}}
$$

The side lobe level of desired Tchebyscheff array is

$$
S L L R C=\max \left|\frac{A F(\theta)}{\max (A F)}\right|_{\theta=\theta_{S L L}}
$$

Where, $\theta_{S L L}=\left(\theta_{0}-\frac{\mathrm{MB}}{2}\right) \cup\left(\theta_{0}+\frac{\mathrm{MB}}{2}\right) \leq \theta \leq 18, \quad \mathrm{MB}$ is the beamwidth of main beam of Tchebyscheff array at scan angle $\theta_{0}$. The cost function, which is to be optimize to reduce the side lobe level, is calculated using equation.5 and equation.6, along with the weight vector ' $\mathrm{W}$ ' given as $[8,9]$

$$
\text { cost }=W[S L L R-S L L R C]
$$

\section{III.SIDE LOBE LEVEL REDUCTION UISNG TCHEBYSCHEFF DISTRIBUTION AND PSO}

PSO is a real coded population based stochastic optimization technique [12-16] that developed on social behavior of bird swarm. PSO is initialized with random particles or solution, evaluate the fitness of each particle using the cost function and directing towards optimum value by updating its present best position pbest, the best value obtained by a particle so far, and global best position gbest, best value achieved in the swarm, through modifying their internal velocities by each particle in the swarm in every iteration. These best values are obtained by updating the velocity as [13]-[15] 
$\operatorname{velocity}(i+1)=\operatorname{velocity}(i)+C_{1} * \operatorname{rand} *\{$ pbest $-\operatorname{position}(i)\}+C_{2} * \operatorname{rand} *\{$ gbest $-\operatorname{position}(i)\}$

$\operatorname{position}(i+1)=\operatorname{position}(i)+\operatorname{velocity}(i+1)$

Here ' $i$ ' is the no. of iterations, 'rand' is a random number between $(0,1)$. c1, c2 are social and cognitive learning factors. The process will iterate until stopping criteria are met.

In this paper, PSO is applied to optimize the cost function (equation.7) for 20-element and 12-element linear Tchebyscheff phased array, keeping inter element distance $d=0.5 \lambda$. It is first observed the radiation pattern of the Tchebyscheff phased array before optimization and simulation has performed using equation.5, for side lobe levels of $-20 \mathrm{~dB}$ and $-25 \mathrm{~dB}$ at different scan angles. In PSO optimization, array pattern was obtained for minimum side lobe level. Then in TD-PSO, the desired values of TD are taken and optimization using PSO is done for minimum SLL using the cost function of equation.7. Simulation also performed for uniform linear phased array antenna using equation. 1 for same number of antenna elements and inter-element spacing using only PSO optimization. Simulated radiation patterns obtained through application of Tchebyscheff Distribution (TD), PSO optimization (PSO) on uniform linear array and TD-PSO on 12 element array at different scan angles are plotted in Fig. 2, Fig. 3.

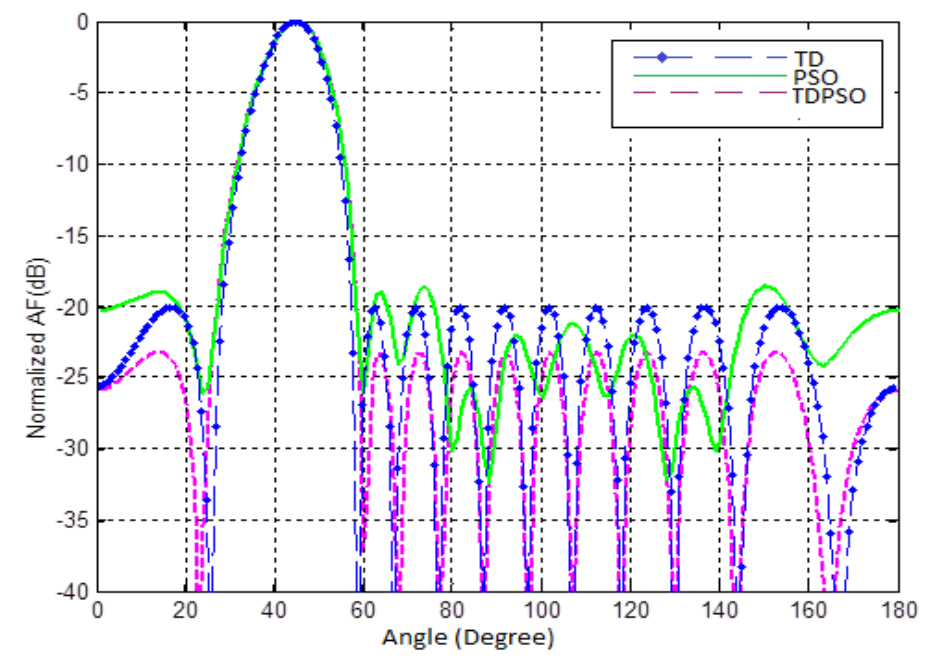

Fig. 2. Normalized array factor of 12 -element array using TD, PSO, TD-PSO at $45^{\circ}$ with SLL $=-20 \mathrm{~dB}$ in TD

The TD-PSO optimized excitation current weight for Tchebyscheff array with maximum SLL -20dB SLL at $\left.\begin{array}{llllllllllll}45^{\circ} \text { tilt angle}[0.44 & 0.52 & 0.60 & 1.01 & 0.98 & 1.00 & 1.02 & 0.99 & 0.75 & 0.72 & 0.37 & 0.34\end{array}\right]$ and $90^{\circ}$ tilt angle $\left[\begin{array}{llllllllllll}0.04 & 0 & 0.37 & 0.51 & 0.68 & 1.01 & 1.00 & 0.98 & 0.83 & 0.73 & 0.46 & 0.29\end{array}\right]$.

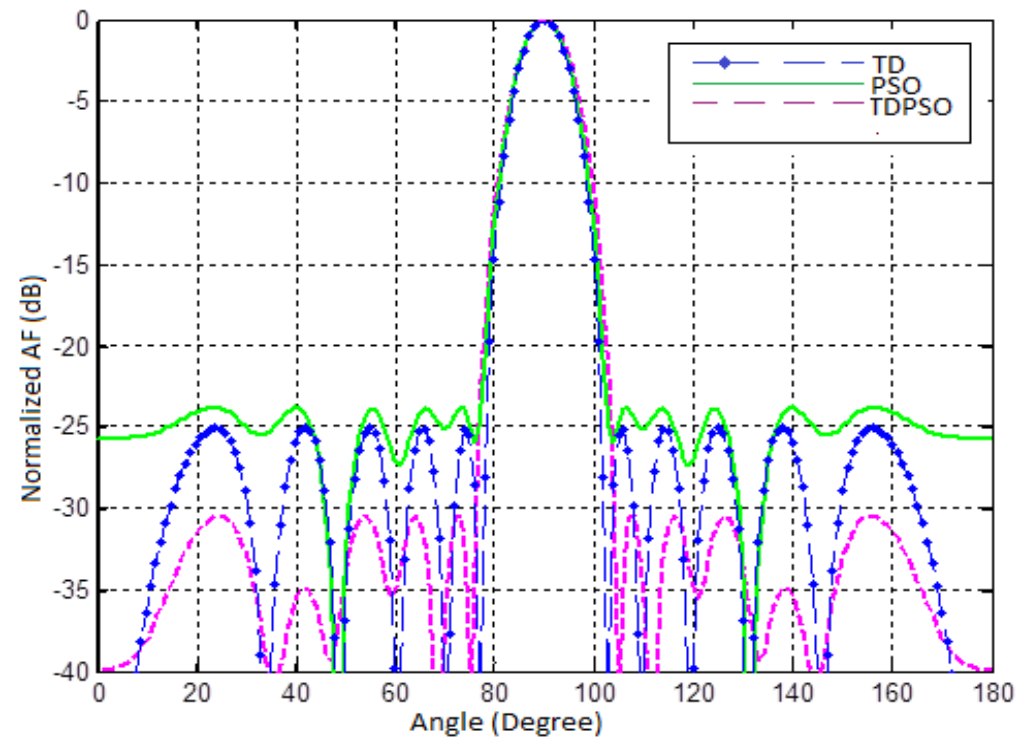

Fig. 3. Normalized array factor of 12 -element array using TD, PSO, TD-PSO at $90^{\circ}$ with SLL $=-25 \mathrm{~dB}$ in TD 
In another case of TD with maximum SLL - $25 \mathrm{~dB}$ TD-PSO optimized excitation current weight at $45^{0}[0.18$ $\left.\begin{array}{llllllllllll}0.24 & 0.49 & 0.63 & 1.00 & 0.97 & 1.01 & 1.00 & 0.98 & 0.68 & 0.47 & 0.28\end{array}\right]$ and at $90^{\circ}\left[\begin{array}{llllll}0.26 & 0.43 & 0.60 & 0.78\end{array}\right.$

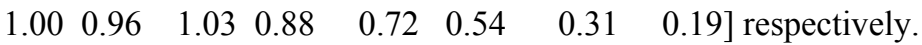

The different array characteristics performances of 12-element optimized linear array and Tchebyscheff array at different tilt angles with their respective maximum side lobe level, half power beamwidth (HPBW) and feeding current amplitude weight are compared and presented in Table I. Feeding current amplitude weights are ratios of currents fed to the antenna elements.

TABLE I. Comparison of Results for 12-element Phased Array Obtained Using TD, PSO and TD-PSO

\begin{tabular}{|l|l|l|l|l|l|l|}
\hline \multirow{2}{*}{$\begin{array}{c}\text { Tilt } \\
\text { Angle } \\
\text { (Deg) }\end{array}$} & \multicolumn{3}{|c|}{ HPBW (Deg) } & \multicolumn{3}{c|}{ Max Side Lobe Level (SLL max $_{\text {) }}$} \\
\cline { 2 - 7 } & TD & PSO & TD-PSO & TD SLL fixed & $\begin{array}{l}\text { Optimized } \\
\text { using PSO }\end{array}$ & $\begin{array}{l}\text { Optimized using } \\
\text { TD-PSO }\end{array}$ \\
\hline 45 & 13.5 & 12 & 15 & $-20 \mathrm{~dB}$ & $-18.85 \mathrm{~dB}$ & $-23 \mathrm{~dB}$ \\
\hline 90 & 9.7 & 10 & 12 & $-20 \mathrm{~dB}$ & $-24.01 \mathrm{~dB}$ & $-26.64 \mathrm{~dB}$ \\
\hline 45 & 17 & 12 & 20 & $-25 \mathrm{~dB}$ & $-18.75 \mathrm{~dB}$ & $-27.02 \mathrm{~dB}$ \\
\hline 90 & 10 & 10 & 10 & $-25 \mathrm{~dB}$ & $-24.01 \mathrm{~dB}$ & $-30.54 \mathrm{~dB}$ \\
\hline
\end{tabular}

Some of the simulated radiation patterns of 20 element uniform linear array, obtained through application of Tchebyscheff Distribution (TD), PSO optimization only and TD-PSO on at different scan angles are shown in Fig. 4, Fig. 5, Fig.6 and in Fig. 7.

The excitation current weight of TD-PSO optimized phased array for TD maximum SLL - $20 \mathrm{~dB}$ at $30^{\circ}$ tilt angle [ [ $\left.\begin{array}{lllllllllllllllllllll}0.30 & 0.37 & 0.31 & 0.37 & 0.46 & 0.45 & 0.60 & 0.63 & 0.61 & 0.56 & 0.63 & 0.62 & 0.60 & 0.44 & 0.48 & 0.41 & 0.35 & 0.30 & 0 & 0.29\end{array}\right]$,

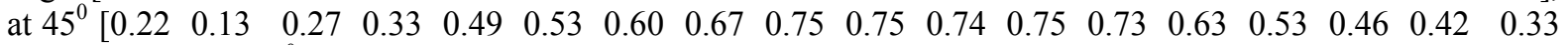

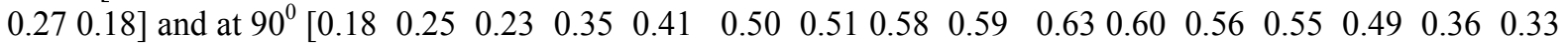
$\left.\begin{array}{llll}0.30 & 0.19 & 0.21 & 0\end{array}\right]$.

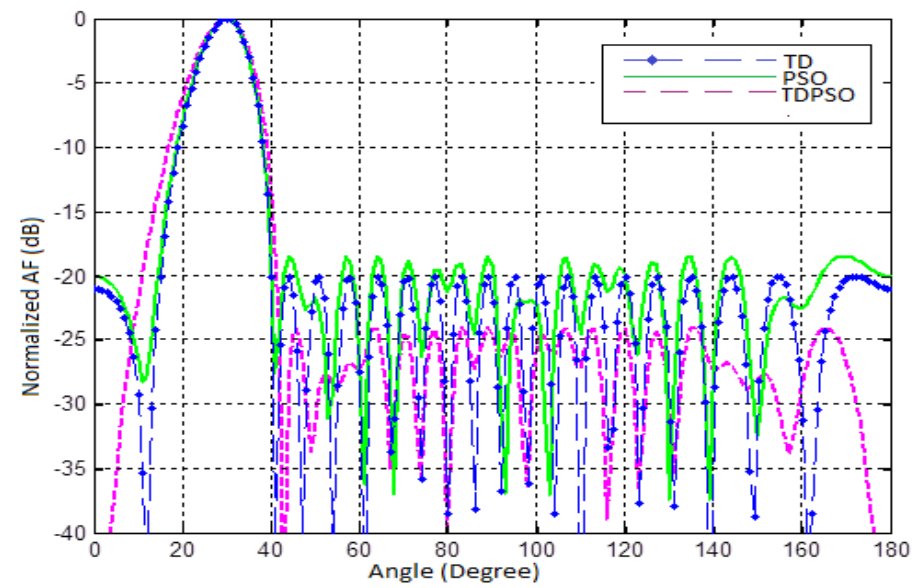

Fig. 4. Normalized array factor of 20-element array using TD, PSO, TD-PSO at $30^{\circ}$ with SLL $=-20 \mathrm{~dB}$ in TD

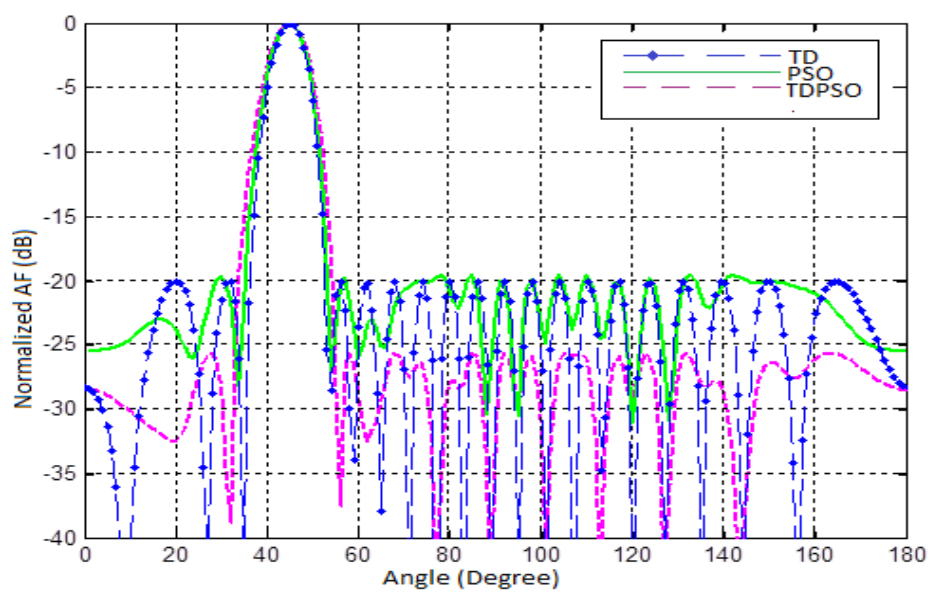

Fig. 5. Normalized array factor of 20-element array using TD, PSO, TD-PSO at $45^{\circ}$ with SLL $=-20 \mathrm{~dB}$ in TD 
In another set of simulation TD SLL fixed at $-25 \mathrm{~dB}$, later the optimization is performed for lowering the SLL and the resultant excitation current weight distribution of TD-PSO optimized phased array for $30^{\circ}$ tilt angle is

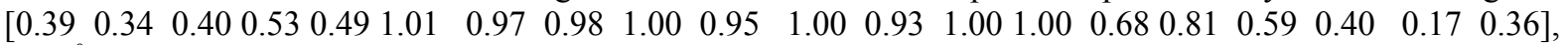
at $45^{0}\left[\begin{array}{llllllllllllllllll}0.02 & 0.08 & 0 & 0.06 & 0.11 & 0.15 & 0.25 & 0.35 & 0.43 & 0.51 & 0.59 & 0.61 & 0.61 & 0.60 & 0.52 & 0.44 & 0.33 & 0.27\end{array}\right.$

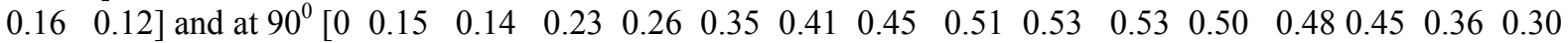
$\left.\begin{array}{llll}0.25 & 0.17 & 0.12 & 0.09\end{array}\right]$.

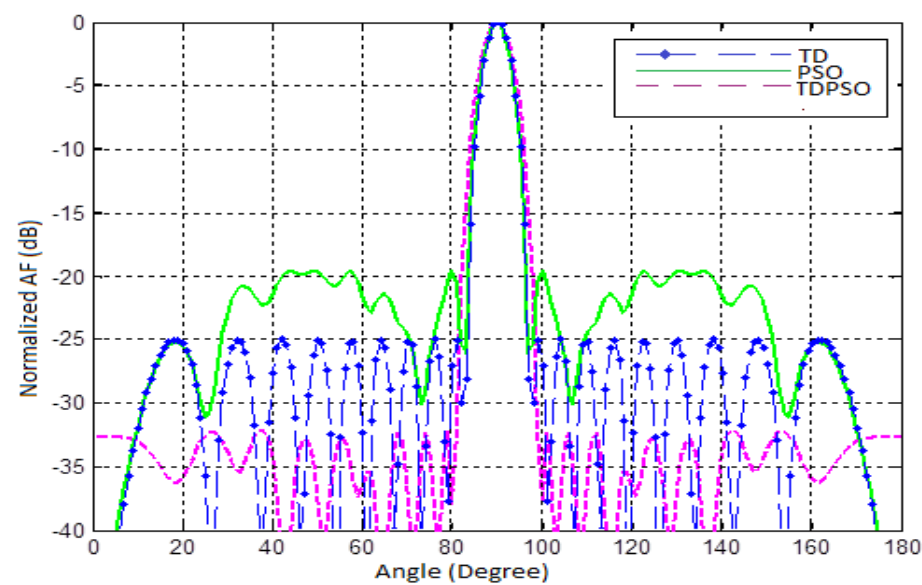

Fig. 6. Normalized array factor of 20-element array using TD, PSO, TD-PSO at $90^{\circ}$ with SLL $=-25 \mathrm{~dB}$ in TD

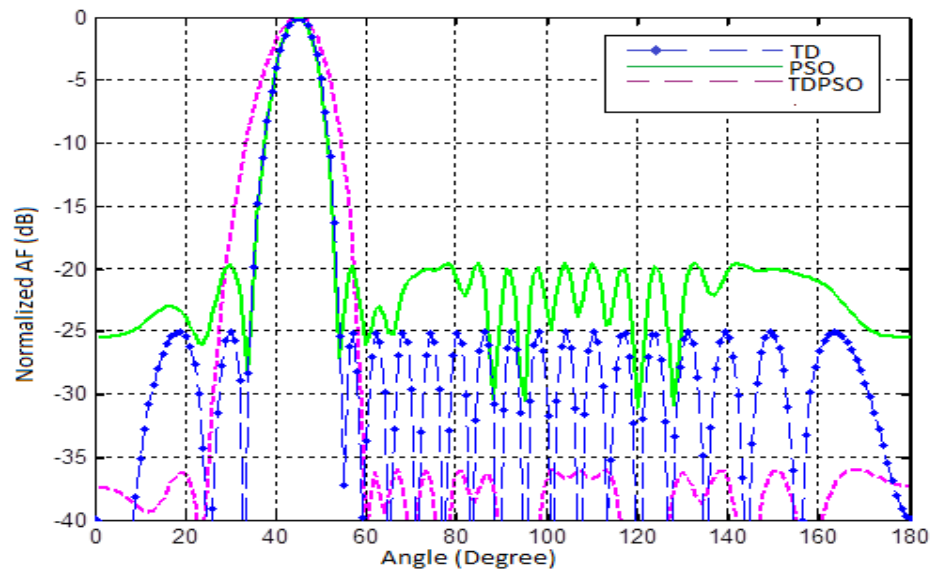

Fig. 7. Normalized array factor of 20 -element array using TD, PSO, TD-PSO at $90^{\circ}$ with SLL $=-25 \mathrm{~dB}$ in TD

The performances of 20-element optimized linear array and Tchebyscheff array at different tilt angles with their respective maximum side lobe level, half power beamwidth (HPBW) and feeding current amplitude weight are compared in Table II respectively.

TABLE III. Comparison of Results for 20-element Phased Array Obtained Using TD, PSO and TD-PSO

\begin{tabular}{|l|l|l|l|l|l|l|}
\hline \multirow{2}{*}{$\begin{array}{c}\text { Tilt } \\
\text { Angle } \\
\text { (Deg) }\end{array}$} & \multicolumn{3}{|c|}{ HPBW (Deg) } & \multicolumn{3}{c|}{ Max Side Lobe Level (SLL max ) } \\
\cline { 2 - 7 } & TD & PSO & TD-PSO & TD SLL fixed & $\begin{array}{l}\text { Optimized } \\
\text { PSO only }\end{array}$ & $\begin{array}{l}\text { Optimized } \\
\text { TD-PSO }\end{array}$ \\
\hline 30 & 11.5 & 11 & 12.5 & $-20 \mathrm{~dB}$ & $-18.84 \mathrm{~dB}$ & $-24.5 \mathrm{~dB}$ \\
\hline 45 & 9.25 & 8.75 & 9.5 & $-20 \mathrm{~dB}$ & $-19.73 \mathrm{~dB}$ & $-26.0 \mathrm{~dB}$ \\
\hline 90 & 5.5 & 5.75 & 6 & $-20 \mathrm{~dB}$ & $-19.81 \mathrm{~dB}$ & $-28.1 \mathrm{~dB}$ \\
\hline 30 & 12.5 & 11 & 12 & $-25 \mathrm{~dB}$ & $-18.84 \mathrm{~dB}$ & $-25.82 \mathrm{~dB}$ \\
\hline 45 & 10 & 8.75 & 11.5 & $-25 \mathrm{~dB}$ & $-19.73 \mathrm{~dB}$ & $-36.03 \mathrm{~dB}$ \\
\hline 90 & 6 & 5.75 & 6.25 & $-25 \mathrm{~dB}$ & $-19.81 \mathrm{~dB}$ & $-32.5 \mathrm{~dB}$ \\
\hline
\end{tabular}

Here, PSO optimization is applied to find the optimum amplitude weight of feeding current of each element in the array so the newly synthesize non uniform amplitude array will produce lower side lobe level than respective Tchebyscheff array with minimal distortion in main beamwidth. PSO optimization is applied on 12-elements and 20-elements uniform linear array along with Tchebyscheff array having side lobe levels of $-20 \mathrm{~dB}$ and $-25 \mathrm{~dB}$. The values of SLL, mentioned in the tables, are the best values, obtained after a large number of simulations for 
a particular scan angle. The graphical plots are drawn for the best values of current coefficients, obtained by the optimization.

The simulation of radiation pattern using PSO is developed through MATLAB software using Intel i5 processor computer. For all of the cases of optimization, the different parameters are considered for optimization such as, the swarm size, maximum no. of iteration, cognitive parameter, social parameter, constriction factor, weight vector are summarized in Table III.

TABLE IIII. Computation Specifications of Optimization Parameters

\begin{tabular}{|l|l|l|l|l|l|}
\hline Algorithm & \multicolumn{2}{|c|}{ Parameters } & Iteration & $\begin{array}{c}\text { No. of } \\
\text { Elements }\end{array}$ & $\begin{array}{c}\text { Average } \\
\text { Computation Time }\end{array}$ \\
\hline PSO & $\begin{array}{l}\text { Swarm } \\
\text { Size - } \\
500\end{array}$ & $\begin{array}{l}\text { Cognitive parameter C1 }=1 \\
\text { Social parameter C2= 4-C1, } \\
\text { Constriction factor C=1, } \\
\text { Inertia weight W= 0 to +1 }\end{array}$ & 500 & 12 & $927.50 \mathrm{sec}$ \\
\hline PSO & $\begin{array}{l}\text { Swarm } \\
\text { Size - } \\
600\end{array}$ & $\begin{array}{l}\text { Cognitive parameter C1 =1 } \\
\text { Social parameter C2=4-C1, } \\
\text { Constriction factor C=1, } \\
\text { Inertia weight W=0 to +1 }\end{array}$ & 500 & 20 & $1083.44 \mathrm{sec}$ \\
\hline TD-PSO & $\begin{array}{l}\text { Swarm } \\
\text { Size - } \\
500\end{array}$ & $\begin{array}{l}\text { Cognitive parameter C1 }=1.5 \\
\text { Social parameter C2 }=4-\mathrm{C} 1, \\
\text { Constriction factor C=1, } \\
\text { Inertia weight W=0 to +1 }\end{array}$ & 500 & 12 & $1006.78 \mathrm{sec}$ \\
\hline TD-PSO & $\begin{array}{l}\text { Swarm } \\
\text { Size - } \\
600\end{array}$ & $\begin{array}{l}\text { Cognitive parameterC1 }=1.5 \\
\text { Social parameter C2= 4-C1, } \\
\text { Constriction factor C=1, } \\
\text { Inertia weight W=0 to +1 }\end{array}$ & 500 & 20 & $1147.38 \mathrm{sec}$ \\
\hline
\end{tabular}

Observing the output of different types of array, it is evident that TD-PSO is producing lowest side lobe level in all the cases with a little expansion in half power beamwidth. Application of PSO optimization on uniform linear array can produce lower SLL but that unable to reach beyond the SLL of TD-PSO optimization.

Cost behaviour of PSO optimized array factor cost for global minimum and local minimum after every iteration for 20 element array at $45^{*}$ scan angle is shown in Fig. 8.

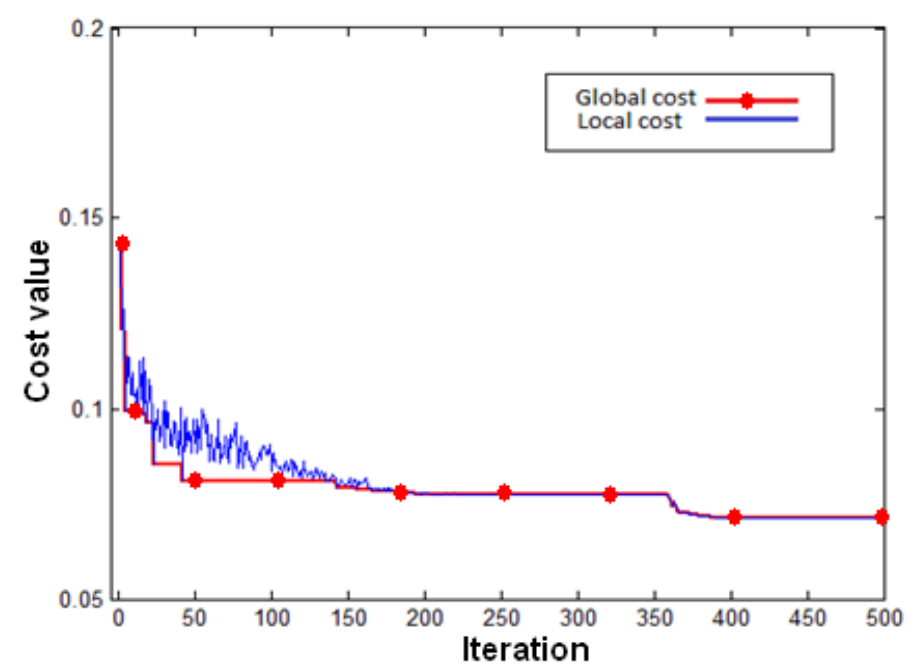

Fig. 8. Variation of cost value for 20-element array using PSO, at scan angle $45^{\circ}$

\section{IV.CONCLUSION}

The optimized Tchebyscheff phased arrays are designed using PSO to reduce side lobe levels. As mentioned in Table 1, that maximum side lobe level of about $5.5 \mathrm{~dB}$ lower than Tchebyscheff array is designed using proposed TD-PSO algorithm for 12-element linear phased array. Whereas in Table 2, maximum side lobe level of about $11 \mathrm{~dB}$ lower than Tchebyscheff array is designed using proposed TD-PSO algorithm for 20-element linear phased array. TD-PSO does not design an array with equal side lobe levels as can be designed using Tchebyscheff distribution. The extreme right columns of Table 1 and Table 2 give the current distributions for 
12-element and 20-element linear phased arrays designed using TD-PSO. This proposed TD-PSO method can initiate a research scope for adaptive beamforming technology in smart antenna where high side lobe is a cause of interference for neighbouring users in a cellular zone. After a large number of simulations, using TD-PSO, it is found that after 400 iterations, in all the cases, the local and global minima values of cost function almost saturate (like, Fig. 8). Therefore stopping criteria is taken as 500 iterations. Also, in Table-3, average computation time is the average time for computation in different scan angles. In different scan angles, maximum variation of computations time is 1 second. The proposed TD-PSO method for array synthesis, after 70 element linear array (as confirmed by simulation), does not show good performance. This is one limitation of the proposed method for a large array.

\section{REFERENCES}

[1] R. S. Elliot, Antenna Theory and Design, Revised Edition, New Jersey, John Wiley, 2003.

[2] C. A. Balanis, Antenna Theory-Analysis and Design, 3rd Edition, John Wiley, 2005.

[3] R. C. Hansen, Phased Array Antennas, 2nd Edition, New Jersy, John Willy \& Sons, 2009.

[4] M. Skolnik, J. Sherman and F. Ogg, "Statistically Designed Density-Tapered Array", IEEE Trans. Antennas and Propagation, vol. 12, no. 4, pp. 408-417, 1964.

[5] S. J. Blank and M. F. Hutt, "On the Empirical Optimization of Antenna Arrays", IEEE Antennas and Propagation Magazine, vol. 47, pp. 58-67, 2005.

[6] P.J. Bevelacqua and C. A. Balanis, "Minimum Side Lobe Levels for Linear Arrays", IEEE Trans. Antennas and Propagation, vol. 55, no. 12, pp. 3442-3449, 2007.

[7] E.C. Jordan, K. G. Balmain, Electromagnetic Waves and Radiating Systems, $2^{\text {nd }}$ edition, PHI, New Delhi, 2013.

[8] G. T. F. de Abreu and R. Kohno, "A Modified Dolph-Chebyshev Approach for the Synthesis of Low Side Lobe Beam patterns with Adjustable Beamwidth”, IEEE Trans. Antennas and Propagation, vol. 51, no. 10, pp. 3014-3017, 2003.

[9] S.A. Babale, D.D. Dajab, K. Ahmad, "Synthesis of a Linear Antenna Array for Maximum Side-Lobe Level Reduction”, International Journal of Computer Applications, vol. 85, no. 6, pp. 24-27, 2014.

[10] S. Das, D. Mandal, R. Kar and S. P. Ghosal, "A New Hybridized Backtracking Search Optimization Algorithm with Differential Evolution for Side Lobe Suppression of Uniformly Excited Concentric Circular Antenna Arrays", International Journal of RF and Microwave Computer -Aided Engineering, vol. 25, no.3, pp. 262-268, 2015.

[11] F. Gunes, and F. Tokan, "Pareto Optimal Synthesis Of The Linear Array Geometry for Minimum Side Lobe Level and Null Control During Beam Scanning", International Journal of RF and Microwave Computer -Aided Engineering, vol. 20, no. 5, pp. 557-566, 2010.

[12] M. Donelli, A. Martini, and A. Massa, "A Hybrid Approach Based on PSO and Hadamard Difference Sets for the Synthesis of Square Thinned Arrays", IEEE Trans. Antennas and Propagation, vol. 57, no. 8, pp. 2491-2495, 2009.

[13] J. Kennedy, and R. C. Eberhart, "Particle Swarm Optimization", Proc. of Int. Conf. Neural Networks, Piscataway, NJ. December 1995, pp. 1942-1948, 1995.

[14] R. C. Eberhart, and Y. Shi, "Particle Swarm Optimization: Developments, Applications and Resources", Proc. Congress of Evolutionary Computation, vol. 1, pp. 81-86, 2001.

[15] J. Robinson, and Y. Rahmat-Samii, "Particle Swarm Optimization in Electromagnetics", IEEE Trans. Antennas and Propagation, vol. 52, no. 2, pp. 397-407, 2004.

[16] P. Nandi, and J. S. Roy, "Optimization of side lobe level of thinned phased array antenna using genetic algorithm and particle swarm optimization", IEEE International WIE Conference in Electrical and Computer Engineering (WIECON-ECE), Dhaka, 19-20 December 2015, IEEE Xplore, pp. 27-30, 2015.

\section{Author Profile}

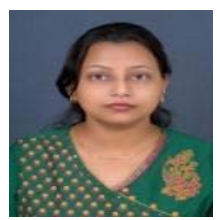

Pampa Nandi received M.Tech ( Electronics and Telecommunication Engg.) degree from KIIT University, Bhubaneswar, India, in 2010. She is presently working towards Ph.D degree at KIIT University She is also working as a Lecturer in KIIT University. Her research interest is mainly focusing on phased array antenna, thinned array, and different optimization techniques.

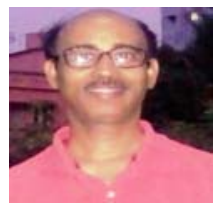

Jibendu Sekhar Roy is a professor in the School of Electronics Engineering, KIIT University, Bhubaneswar, Odisha, India. From 1998 to 2009, he was lecturer, reader and professor in the ECE department of Birla Institute of Technology, Mesra, Ranchi, India. He has received $\mathrm{Ph}$. D. degree from the Department of Electronics \& Telecommunication Engineering, Jadavpur University, Calcutta, India in 1991. From 1991 to 1993, he was a post-doctoral research associate of CNRS, Govt. of France in IRCOM, University of Limoges, France. From 1994 to 1998, he was a research associate of CSIR in ETCE department, Jadavpur University, Calcutta. His research interest includes microwave and millimeterwave antennas for wireless communication, optimization of thinned array antenna, smart antennas, channel assignment \& MIMO-OFDM algorithms, cognitive radio. Dr. Roy has published about 200 papers in international journals and symposia. He has presented Invited lectures/research papers in workshops and symposia in various Institutes in India and other countries, like, France, USA, Indonesia, Italy, Denmark, Czech Republic and South Korea. The name of Dr JS Roy has been listed in 2012 Marquis World Who's Who. 